\title{
Çelik Kiriş ve Kolon Plastik Mafsal Parametrelerinin ve Şekil Değiştirme Sınır Değerlerinin Karşılaştırmalı İncelenmesi
}

\author{
Mustafa Berker ALICIOĞLU ${ }^{1 *}$ (D) \\ ${ }^{1}$ Manisa Çevre, Şehircilik ve İklim Değişikliği İl Müdürlüğ̈̈, Yunusemre, Manisa, Türkiye. \\ *berker.alicioglu@gmail.com
}

\begin{abstract}
Özet
Yapılardaki deprem hasarının tahmini, can ve mal kaybını önleme açısından oldukça önemlidir. Hasar tahmini, plastik mafsal parametrelerinin ve şekil değiştirme sınır durumlarının gerçek yapı davranışını yansıtması oranında başarıı olmaktadır. Yapı tasarımında ve mevcut yapı değerlendirmesinde çeşitli standartlar ile plastik mafsal parametreleri ve şekil değiştirme sınır değerleri belirlenmiştir. Federal Acil Durum Yönetim Kurumu (FEMA) ve Amerikan İnşaat Mühendisleri Birliği (ASCE) bu alanda öncü olmuşlardır. Deprem yönetmeliklerimiz içerisinde ilk kez Türkiye Bina Deprem Yönetmeliği 2018' de (TBDY-2018) çelik yapı elemanları için şekil değiştirme sınır değerlerine yer verilmiştir. Bu çalışma ile FEMA 356, ASCE 41-06, ASCE 41-13 standartlarında ve TBDY-2018' de yer alan çelik kiriş ve kolon için plastik mafsal parametreleri ve şekil değiştirme sınır değerleri karşıllaştırılmıştır. TBDY-2018 ile Amerikan standartları arasındaki ilişki ve TBDY-2018' in eksik yönleri belirlenmiştir. İki farklı nümerik analiz ile Amerikan standartlarının ve TBDY-2018' in belirlediği yapısal hasar düzeyleri arasındaki farklar ortaya konmuştur. FEMA 356 ve ASCE 41-06 standartları, ASCE 41-13 standardı ve TBDY-2018 dikkate alınarak yapılacak hasar tahminlerinde kolon ve kiriş elemanları için farklı hasar durumlarının tahmin edileceği tespit edilmiştir.
\end{abstract}

Anahtar Kelimeler: çelik yapı, plastik mafsal, yapısal hasarı, şekil değiştirme

\section{Comparative Investigation of Plastic Hinge Parameters and Strain Limit States of Steel Beam and Column}

\begin{abstract}
Estimation of earthquake damage on structures is quite important in terms of preventing loss of life and property. Damage estimation is successful at the rate that plastic hinge parameters and strain limit states reflect actual structure behavior. In building design and evaluation of the existing building, plastic hinge parameters and strain limit states have been determined with various standards. The Federal Emergency Management Agency (FEMA) and the American Association of Civil Engineers (ASCE) have been pioneers in this field. For the first time among our earthquake codes, Strain limit states are given for members of steel structures in the Turkish Seismic Code for Buildings 2018 (TSCB-2018). With this study, plastic hinge parameters and strain limit states of steel beam and column in FEMA 356, ASCE 41 -
\end{abstract}


06, ASCE 41-13, and TSCB-2018 have been compared. The relationship between TBDY-2018 and American standards and the deciencies of TBDY-2018 have been determined. The differences between the earthquake damage levels determined by the American standards and the TBDY-2018 have been revealed by two different numerical analyses. It has been determined that different limit states will be estimated for column and beam elements in the damage estimates to be made taking into account FEMA 356 and ASCE 41-06 standards, ASCE 41-13 standard and TBDY-2018.

Keywords: steel structure, plastic hinge, earthquake damage, strain

\section{GíRiş}

Yapılar, ekonomik ömürleri boyunca çeşitli yüklere maruz kalırlar. Yapılara etkiyen dış etkenlerin başında deprem yer hareketi gelmektedir. Yapı sistemindeki düzensizlikler, tasarım hataları ve ekonomik ömrün tamamlanmış olması yapıların depremde hasar görmesine neden olmuştur. Depremin yapılar üzerinde yıkıcı etkisi olduğu bilindiğinden araştırmacılar, şehirlerin deprem risklerini belirlemeye çalışmışlardır. [1] ile kentleşme ve nüfus yoğunluğunun deprem riski yüksek bölgelerde arttığı belirtilerek Hırvatistan'daki şehirlerin deprem riskinin bina bazında belirlenmesine yönelik bir tahmin modeli önerilmiştir. [2] ile Kolombiya'nın üç büyük şehrindeki konut binalarının deprem risk değerlendirmesi yapılmıştır. Cali' deki ekonomik kaybın Bogota' ve Medellín' den daha fazla olacağ 1 tahmin edilmiştir. Yapıların deprem performanslarının belirlenmesi, şehirlerin deprem risklerinin değerlendirilmesinde önemli bir unsur olarak karşımıza çıkmaktadır $[1,2]$.

Yapılan literatür araştırmasıyla çelik yapı deprem performansının tahmin edilmesi ve performans1 etkileyen unsurlar açısından çeşitli çalışmaların yapıldığ 1 görülmüştür. 1/8 ölçekli iki adet dört katlı düzlem çelik çerçevenin göçme durumu sayısal olarak tahmin edilmiştir [3]. Geniş başlıklı çelik kirişlerin dönme kapasitelerinin ve sünek davranışlarının tahminine yönelik bir dizi çalışma yapılmıştır [4, 5]. Çelik bir kolonun temel birleşimi ele alınmıştır. Birleşimin dönme kapasitesini teorik bir model üzerinden tahmin etmeye çalışmışlardır [6]. Alın levhalı kolon-kiriş birleşimlerinin analizi ile göçme durumları tahmin edilmiştir [7]. Süneklik etkisinin moment aktaran çelik çerçevelerin sismik performansına olan etkisi incelenmiştir [8]. Yapısal çelik elemanların şekil değiştirme kapasitelerini ve başlık narinliğinin dönme kapasitesine olan etkisi incelemiştir [9]. Geniş başlıklı kolon elemanlarında döngüsel davranış ve plastik mafsal oluşumu analitik olarak ele alınmıştır [10]. Çalışmada W kesit profillerin sonlu eleman modelleri kullanılmıştır. [11] ile çelik elemanlar için Eurocode (EC) 8-3' de tanımlanan şekil değiştirme sınır değerleri incelenmiştir. Plastik dönme kapasiteleri, ASCE 41-06 ve ASCE 41-13 standartlarıla karşılaştırılmıştır. Betonarme elemanlar için Deprem Bölgelerinde Yapılacak Binalar Hakkında Yönetmelik (DBYBHY-2007) ile TBDY-2018'deki kesit hasar sınır durumlarının karşılaştırması yapılmıştır [17]. [18] ile malzeme modellemesini ve şekil değiştirme sınırlarını dikkate alan gelişmiş bir analiz yöntemi ile çelik çerçeve tasarımı yapılmıştır.

Yapısal çelik ile üretilen yapılar, çeliğin sünek davranışından dolayı yüksek şekil değişimleri yapabilir ve plastik teoriye göre tasarlanabilirler [19]. Çelik yapıların deprem performaslarının tahmininde malzeme davranışının dikkate alınması ve geometri değişimlerinin denge denklemlerine eklenmesi önem taşımaktadır. Malzemenin doğrusal olmayan davranışının göz önüne alınması, plastik mafsal tanımıyla mümkün olmaktadır. Geometri değişimlerinde ise ikinci mertebe etkileri dikkate alınır [20, 21].

Yapının deprem performansının belirlenebilmesi için yapısal elemanlara plastik mafsal tanımı yapılarak hangi kesit tesiri etkisinde yapısal elemanlarda ne ölçüde hasar oluşacağının öngörülmesi gerekmektedir. Plastik mafsal tanımı, plastik mafsal modelleme parametreleri ile yapılmaktadır. Şekil değiştirme sınır değerleri, deprem etkisi altındaki elemanlarda oluşan hasarın ne ölçüde olacağının tahmininde kullanılmaktadır. Doksanlı yıllardan bu yana yapı tasarımında ve mevcut yapı değerlendirmesinde çeşitli standartlar ile plastik mafsal modellemesine ilişkin parametreler ve şekil değiştirme sınır değerleri belirlenmiştir. 
Plastik mafsal modelleme parametreleri ve şekil değiştirme sınır değerlerinin veri olarak tasarımcılara sunulması açısından Federal Acil Durum Yönetim Kurumu (Federal Emergency Management Agency FEMA) ve Amerikan İnşaat Mühendisleri Birliği (American Society of Civil Engineers - ASCE) öncü olmuşlardır. Deprem yönetmeliklerimiz içerisinde ise ilk kez, Türkiye Bina Deprem Yönetmeliğinde (TBDY-2018) çelik yapı elemanları için şekil değiştirme sınır değerlerine yer verilmiştir. Şekil 1 ile FEMA, ASCE standartlarına ve TBDY-2018' e ait zaman akış şemasının gösterimi yapılmıştır.

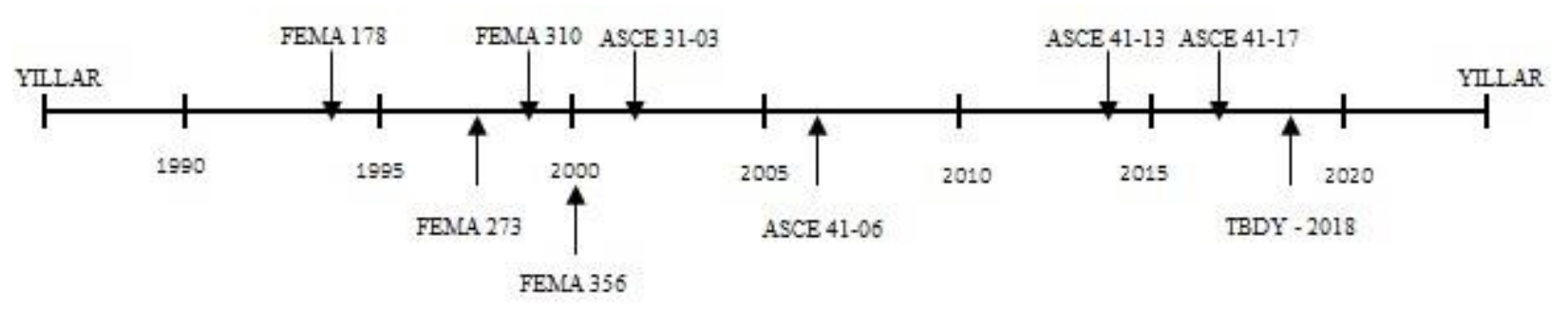

Şekil 1. Zaman akış şeması

TBDY-2018' de plastik mafsal modelleme parametrelerinin bulunmadığı görülmüştür. Öte yandan TBDY-2018' in EK 5C' si, çelik elemanlar için izin verilen şekil değiştirme sınırları hakkında bilgi vermektedir. Tablo 5C.1 ile çelik kirişlerde plastik dönme sınırları ve Tablo 5C.2 ile çelik kolonlarda plastik dönme sınırları tanımlanmıştır. Yapılan kapsamlı literatür araştırmasıyla Tablo 5C.1 ve Tablo 5C.2' deki verilerin, farklı standartlar ile karşılaştırılarak irdelenmediği anlaşılmıştır.

Bu çalışmada FEMA 356, ASCE 41-06, ASCE 41-13 standartlarında ve TBDY-2018' de yer alan çelik kiriş ve kolon elemanları için plastik mafsal modelleme parametreleri ve şekil değiştirme sınır değerleri karşılaştırılmıştır. TBDY-2018 ile Amerikan standartları arasındaki ilişki ve TBDY-2018' in eksik yönleri belirlenmiştir. Çalışma kapsamında tek katlı düzlem çelik bir çerçeve ile iki katlı çelik bir yapının kolon ve kiriş elemanlarındaki plastik mafsal oluşumu ve elemanlardaki hasar düzeyleri incelenmiştir.

İki farklı nümerik analiz ile Amerikan standartlarının ve TBDY-2018' in belirlediği yapısal hasar düzeyleri arasındaki farklar ortaya konmuştur. TBDY-2018'de plastik mafsal parametrelerinin olmadığı, hasar düzeyleri arasında farklılıklar olduğu ve beklenen eğilme dayanımı hesabı için denklem eklenmesi gerektiği tespit edilmiştir.

\section{MODELLEME PARAMETRELERI VE KABUL KRITTERLERİ}

Çelik Yapıların Tasarım, Hesap ve Yapımına Dair Esaslar (ÇYTHYDE-2018) ile plastik mafsal, doğrusal elastik olmayan şekil değiştirmelerin yığıldığı bölge olarak tanımlanmıştır. Modelleme parametreleri, plastik mafsal tanımında kullanılan parametreler olup akma dönmesi ve artık dayanım oranından oluşmaktadır. Akma dönmesi, akma anında kesitte meydana gelen dönme değeri iken artık dayanım oranı, hasarlı bir kesitin göçmeden taşıyabileceği yük oranı olarak tanımlanır [27].

Plastik mafsal tanımında akma dönmesinin ve beklenen eğilme dayanımının hesaplanması gerekmektedir. Plastik mafsalların modellenmesine ve mafsalların ne ölçüde şekil değiştirdiğine ilişkin çeşitli standartlarda modelleme parametrelerine ve şekil değiştirme sınır değerlerine yer verilmiştir. Şekil değiştirme sınır değerleri, FEMA ve ASCE standartlarında kabul kriterleri olarak adlandırılmışken TBDY-2018' de şekil değiştirme sınırları olarak adlandırılmıştır. 


\subsection{Akma Dönmesinin Hesaplanması}

Kolon ve kiriş elemanları için akma dönmesinin gösterimi, Şekil 2 ile yapılmıştır. Şekil 2'de yer alan $\theta$ elastik ve plastik dönme miktarının toplamını, $\theta y$ akma dönmesini, $\Delta$ elastik ve plastik deplasmanın toplamını, $\Delta y$ akmadaki deplasmanı, $L$ eleman uzunluğunu ifade etmektedir $[13,14,25]$.
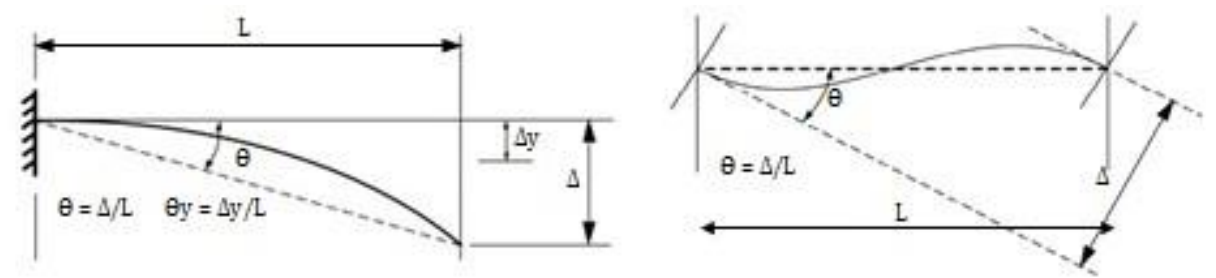

Şekil 2. Kesit dönme tanımları

FEMA-356, ASCE 41-06 ve ASCE 41-13 standartlarında kiriş akma dönmesi $(\Theta y)$, (1) denklemi ile TBDY-2018'de (2) denklemi ile hesaplanmaktadır. (1) denklemindeki $Z$, kesit plastik modülü $F y e$, malzemenin beklenen akma dayanımı, $l b$, kiriş uzunluğu, $E$, elastisite modülü, $I b$, kiriş atalet momenti ve (2) denklemindeki $W p$, kesit plastik modülü olarak tanımlanır. (2) denklemindeki diğer ifadeler, (1) denklemindeki ile aynıdır.

$$
\begin{aligned}
& \theta_{y}=\frac{Z F_{y e} l_{b}}{6 E I_{b}} \\
& \theta_{y}=\frac{W_{p} F_{y e} l_{b}}{6 E I_{b}}
\end{aligned}
$$

FEMA-356, ASCE 41-06 ve ASCE 41-13 standartlarında kolon akma dönmesi $(\Theta y)$, (3) denklemi ile TBDY-2018'de (4) denklemi ile hesaplanmaktadır. (3) denklemindeki, $l c$, kolon uzunluğu, $I c$, kolon atalet momenti, $P$, mevcut eksenel yük, $P y e$, kolonun eksenel akma yükü, (4) denklemindeki $l k$, kolon uzunluğu, $I k$, kolon atalet momenti olarak tanımlanır.

$$
\begin{aligned}
& \theta_{y}=\frac{Z F_{y e} l_{c}}{6 E I_{c}}\left(1-\frac{P}{P_{y e}}\right) \\
& \theta_{y}=\frac{W_{p} F_{y e} l_{k}}{6 E I_{k}}\left(1-\frac{P}{P_{y e}}\right)
\end{aligned}
$$

(3) denkleminde bulunan Pye, kolonun eksenel akma yükü olup (5) denklemi ile hesaplanmaktadır [13, 14, 25]. (5) denklemindeki $A g$, kesit alanı olarak tanımlanır.

$$
P_{y e}=A_{g} F_{y e}
$$

\subsection{Beklenen Eğilme Dayanımının Hesaplanması}

FEMA-356, ASCE 41-06 ve ASCE 41-13 standartlarında kiriş elemanları için beklenen eğilme dayanımı (MCE), (6) denklemi ile hesaplanmaktadır.

$$
M_{C E}=Z F_{y e}
$$


FEMA-356, ASCE 41-06 ve ASCE 41-13 standartlarında kolon elemanları için beklenen eğilme dayanımı (MCE) (7) denklemi ile hesaplanmaktadır.

$$
M_{C E}=1.18 Z F_{y e}\left(1-\frac{P}{P_{y e}}\right)
$$

TBDY-2018' de kolon ve kiriş elemanları için plastik mafsal tanımlamasına yönelik beklenen eğilme dayanımına ilişkin herhangi bir denklem önerilmemiştir.

\subsection{Standartlardaki Modelleme Parametreleri ve Kabul Kriterleri}

FEMA 356, ASCE 41-06 ve ASCE 41-13 standartlarında yapısal çelik bileşenlerin hasar sınır durumlarının değerlendirilmesi, doğrusal ve doğrusal olmayan prosedür olmak üzere ikiye ayrılmaktadır. Doğrusal analiz ile değerlendirme yapılması durumunda doğrusal prosedür kabul kriterleri, doğrusal olmayan analiz ile değerlendirme yapılması durumunda ise doğrusal olmayan prosedür kabul kriterleri kullanılmaktadır.

Şekil 3 ile genelleştirilmiş kuvvet-deformasyon grafiğinin ve kabul kriterlerinin gösterimi yapılmıştır. Grafikteki a ve b plastik dönme açısı cinsinden modelleme parametreleriyken c, artık dayanım oranıdır. $Q$, kuvveti $Q y$ ise akmadaki kuvveti simgelemektedir. Eğilme etkisiyle plastik mafsal oluşan kesitler için Q, eğilme momentine karşılık gelmektedir. Şekil değiştirme sınır değerleri Immediate Occupancy (IO), Life Safety (LS) ve Collapse Prevention (CP) olarak adlandırılırlar (FEMA-356; ASCE 41-06; ASCE 4113).

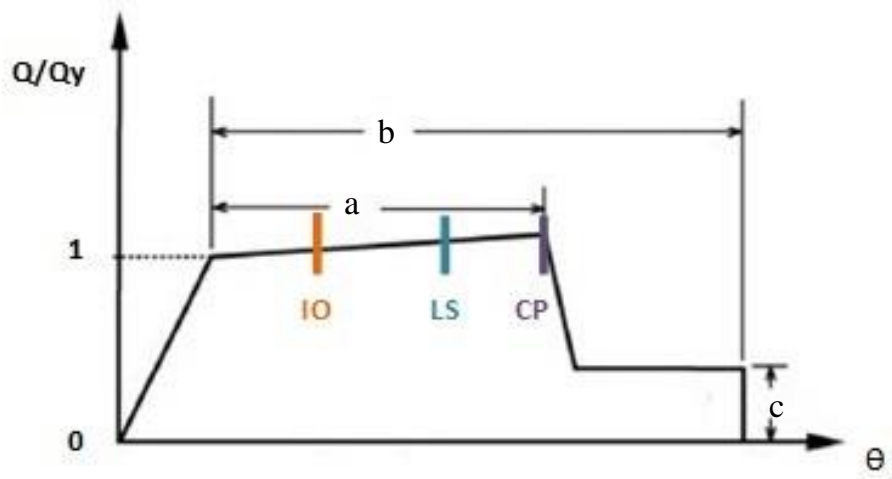

Şekil 3. Genelleştirilmiş kuvvet-deformasyon ilişkisi ve kabul kriterleri

Tablo 1 ile FEMA 356, ASCE 41-06 ve ASCE 41-13 standartlarında yer alan kiriş ve kolon elemanları için doğrusal olmayan prosedür kapsamında verilmiş olan modelleme parametrelerinin ve kabul kriterlerinin gösterimi yapılmıştır. Tablo 2'de TBDY-2018' deki kabul kriterlerine (şekil değiştirme sınırları) yer verilmiştir. TBDY-2018 ile modelleme parametresi için herhangi bir öneride bulunulmamıştır.

Çelik bir kesit için Tablo 1'deki bf başlık genişliğini, tf başlık kalınlığını, $h$ kesit yüksekliğini, tw gövde kalınlığını, $P_{C L}$ beklenen eksenel basınç dayanımını, $P$ eksenel yükü ifade etmektedir. Tablo 1' deki (*) verileri, ASCE 41-13 standardına aittir. (*) verilerinin haricinde kalan diğer veriler, bu üç standart için ortaktır. Tablo 1 incelendiğinde kiriş ve kolon elemanları için FEMA 356 ve ASCE 41-06 standartlarındaki modelleme parametrelerinin ve kabul kriterlerinin aynı olduğu görülmektedir. ASCE 4113 standardındaki kabul kriterleri ise FEMA 356 ve ASCE 41-06 standartlarından farklıdır. Yine Tablo 1 incelendiğinde kiriş elemanı için modelleme parametrelerinin ve kabul kriterlerinin kesitin narinliği ile ilgili olduğu, kolon elemanı için bu parametrelerin ve kriterlerin hem kesit narinliği hem de eksenel yük düzeyi ile ilgili olduğu görülmektedir. Benzer durum, TBDY-2018 için de geçerlidir. 
Tablo 1. FEMA 356, ASCE 41-06, ASCE 41 - 13'deki doğrusal olmayan prosedür için modelleme parametreleri ve kabul kriterleri

\begin{tabular}{|c|c|c|c|c|c|c|}
\hline \multirow{3}{*}{$\begin{array}{l}\text { FEMA 356, ASCE 41- } \\
\text { 06, ASCE } 41-13 \\
\text { Eleman/Etki }\end{array}$} & \multicolumn{3}{|c|}{ Modelleme Parametreleri } & \multicolumn{3}{|c|}{ Kabul Kriterleri } \\
\hline & \multicolumn{2}{|c|}{$\begin{array}{l}\text { Plastik Dönme } \\
\text { Açısl, Radyan }\end{array}$} & \multirow{2}{*}{$\begin{array}{l}\text { Artık } \\
\text { Dayanım } \\
\text { Oranı } \\
\text { c }\end{array}$} & \multicolumn{3}{|c|}{ Plastik Dönme Açısı, Radyan } \\
\hline & a & b & & IO & LS & $\mathbf{C P}$ \\
\hline Kiriş-Eğilme & & & & & & \\
\hline $\begin{array}{l}\text { i. } b f / 2 t f \leq 52 / \sqrt{F_{y e}} \text { ve } \\
h / t w \leq 418 / \sqrt{F_{y e}}\end{array}$ & $9 \theta y$ & $11 \theta y$ & 0,6 & $1 \theta y$ & $\begin{array}{l}6 \theta y \\
9 \theta y^{*}\end{array}$ & $\begin{array}{l}8 \theta y \\
11 \theta y^{*}\end{array}$ \\
\hline $\begin{array}{l}\text { ii. } b f / 2 t f \geq 65 / \sqrt{F_{y e}} \text { ya } d a \\
h / t w \geq 640 / \sqrt{F_{y e}}\end{array}$ & $4 \theta y$ & $6 \theta y$ & 0,2 & $0,25 \theta y$ & $\begin{array}{l}2 \theta y \\
3 \theta y^{*}\end{array}$ & $\begin{array}{l}3 \theta y \\
4 \theta y^{*}\end{array}$ \\
\hline
\end{tabular}

iii. Diğer durumda

Hem başlık narinliği (birinci terim) hem de gövde narinliği (ikinci terim) için i ve ii satırlarındaki değerler arasında doğrusal enterpolasyon yapılacak ve elde edilen en düşük değer kullanılacaktır.

\section{Kolon-Ĕ̆ilme}

$P / P_{C L}<0,20$

i. $b f / 2 t f \leq 52 / \sqrt{F_{y e}}$ ve $h / t w \leq 300 / \sqrt{F_{y e}}$

ii. $b f / 2 t f \geq 65 / \sqrt{F_{\text {ye }}}$ ya $d a$ $h / t w \geq 460 / \sqrt{F_{y e}}$

iii. Diğer durumda

Kolon-Eğilme

$0,20 \leq P / P C L \leq 0,50$

i. $b f / 2 t f \leq 52 / \sqrt{F_{y e}}$ ve

$h / t w \leq 260 / \sqrt{F_{y e}}$

ii. $b f / 2 t f \geq 65 / \sqrt{F_{y e}}$ ya $d a$ $h / t w \geq 400 / \sqrt{F_{y e}}$

iii. Diğer durumda
$9 \theta y$

$11 \theta y$

$4 \theta y$

$6 \theta y$

0,2

$10 y$

$90 y^{*}$

$0,25 \theta y$

$2 \theta y$
$3 \theta y^{*}$

Hem başlık narinliği (birinci terim) hem de gövde narinliği (ikinci terim) için i ve ii satırlarındaki değerler arasında doğrusal enterpolasyon yapılacak ve elde edilen en düşük değer kullanılacaktır.

$\begin{array}{lllll}11(1-1.7 & 17(1-1.7 & 0,2 & 0,25 \theta y & \\ \left.P / P_{C L}\right) \theta y & P / P C L) \theta y & & & 14(1-1.7 \\ & & & & P / P C L) \theta y^{*} \\ & & & & 0,5 \theta y \\ 1 \theta y & 1,5 \theta y & 0,2 & 0,25 \theta y & 1,2 \theta y^{*}\end{array}$

$11(1-1.7 P / P C L)$

$\theta y$

$17(1-1.7 P / P C L)$

$\theta y^{*}$

$0,8 \theta y$

$1,2 \theta y^{*}$

Hem başlık narinliği (birinci terim) hem de gövde narinliği (ikinci terim) için i ve ii satırlarındaki değerler arasında doğrusal enterpolasyon yapılacak ve elde edilen en düşük değer kullanılacaktır.

TBDY-2018' de kiriş ve kolon elemanları için izin verilen şekil değiştirme sınırları, farklı performans düzeyleri (kabul kriterleri) için plastik dönme cinsinden verilmiştir. Çelik kirişlerde ve kolonlarda süneklik düzeyi, TBDY-2018' deki Tablo 9-3' de tanımlanan en kesit koşulları dikkate alınarak belirlenmekte olup $\mathrm{P} / \mathrm{P}_{\mathrm{C}}>0,50$ koşulunda olan kolonlarda doğrusal olmayan şekil değiştirmelere izin verilmemektedir. Tablo 2, TBDY-2018' deki Tablo 5C.1. ile 5C.2. yardımıyla oluşturulmuştur. Tablo 2' deki $P_{C}$ beklenen eksenel basınç dayanımını ve $P$ eksenel yükü ifade etmektedir.

FEMA 356, ASCE 41-06 ve ASCE 41-13' de kabul kriterleri Immediate Occupancy (IO), Life Safety (LS) ve Collapse Prevention (CP) olarak tanımlanırken TBDY-2018' de SH, KH ve GÖ olarak tanımlanmıștır. TBDY-2018' de SH sınırlı hasar performans düzeyini, KH kontrollü hasar performans düzeyini ve GÖ göçmenin önlenmesi hasar performans düzeyini ifade etmektedir. IO, SH' ye LS, KH' ye ve CP, GÖ performans düzeyine karşılık gelmektedir. SH, bina taşıyıcı sistem elemanlarında sınırlı düzeyde hasarın meydana geldiğini, doğrusal olmayan davranışın sınırlı kaldığını; KH, can güvenliğini 
sağlamak üzere bina taşıyıcı sistem elemanlarında çok ağır olmayan ve çoğunlukla onarılması mümkün olan hasarın olduğunu ve GÖ, bina taşıyıcı sistem elemanlarında ileri düzeyde ağır hasarın olduğunu işaret etmektedir (TBDY-2018).

Tablo 2. TBDY-2018'deki doğrusal olmayan prosedür için modelleme parametreleri ve kabul kriterleri

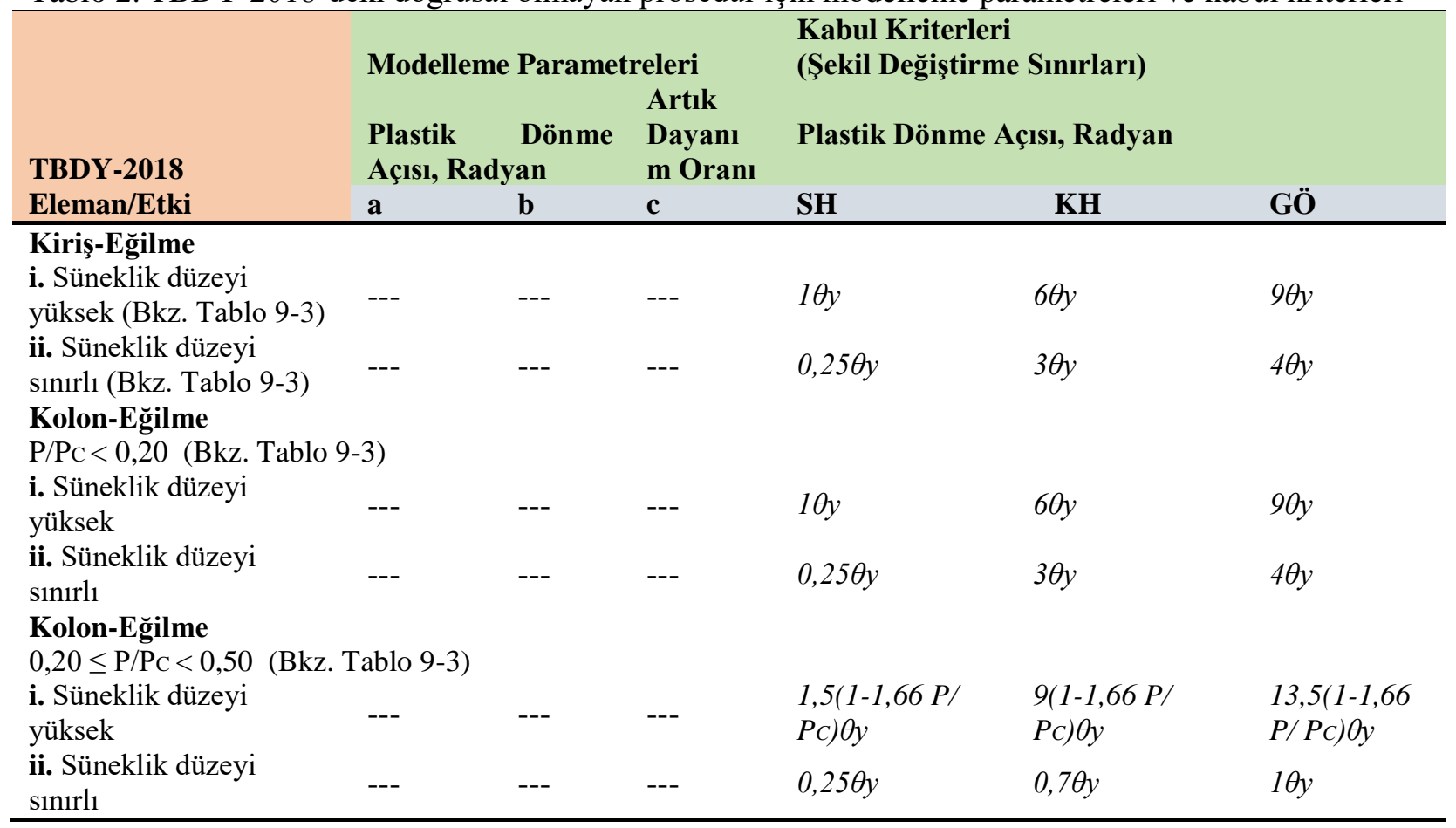

\section{NÜMERİK ÇALIŞMA}

Nümerik çalışma, yapısal analiz ve tasarım yapabilen Sap2000 bilgisayar programı ile yapılmıştır. Yapısal çelik malzemesi olarak programın öntanımlı malzeme listesinden tercih yapılmış olup, EN 19931-1' e göre EN 10025-2 standardındaki S275 kalitesinde malzeme kullanılmıştır. Malzemeye ait gerilme şekil değiştirme eğrisi, Şekil 4 ile gösterilmiştir. Çalışmada düzlem çelik bir çerçeve ve iki katlı çelik bir yapı ele alınmıştır.

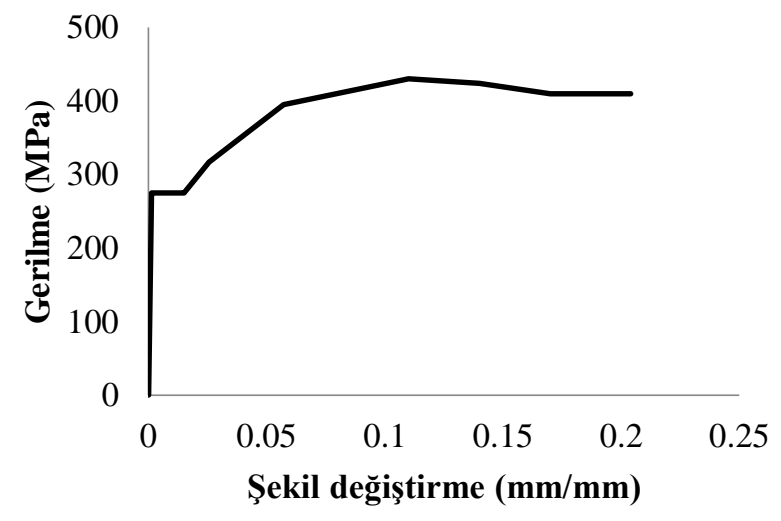

Şekil 4. Yapısal çelik malzemesi 


\subsection{Düzlem Çelik Çerçeve}

Yap1, tek açıklıklı tek katlı düzlem çelik çerçevedir. Açıklık 5 metre ve kat yüksekliği 4 metredir. Kolonlar ve kiriş kesitleri, kuvvetli eksenleri yönünde analiz edilmişlerdir. Çerçeve zemine ankastre bağlanmıştır. Kiriş üzerinde (-Z) yönlü 260 kN, $60 \mathrm{kN}$ ve $700 \mathrm{kN}$ noktasal yük bulunmaktadır. Çerçeve üzerindeki düşey yükler ve yanal yük uygulama noktaları, Şekil 5.a ile gösterilmiştir. $60 \mathrm{kN}$ değerindeki tekil yük, kiriş açıklığının orta noktasındadır. Çerçeve zati ağırlığı ve kiriş yüklerinden oluşan tek bir kombinasyon altında ÇYTHYDE-2018' e göre boyutlandırılmıştır. Boyutlandırmada Yük ve Dayanım Katsayıları ile Tasarım (YDKT) yaklaşımı kullanılmış olup, kolonlar için Bölüm 11' deki, kirişler için Bölüm 9' daki esaslar dikkate alınmıştır. Kolonlar HE240A ve kirişler HE200A olarak tasarlanmıştır. Zemin kat kolonları için P/PCL oranı sol kolon için 0,103 ve sağ kolon için 0,490 olarak hesaplanmış olup, Şekil 5.b ile kolonlardaki P/PCL oranları gösterilmiştir.

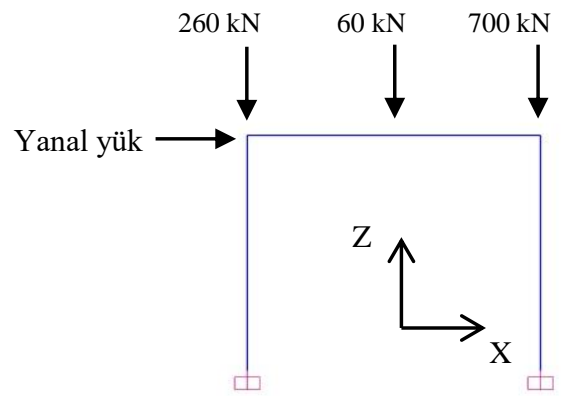

a.

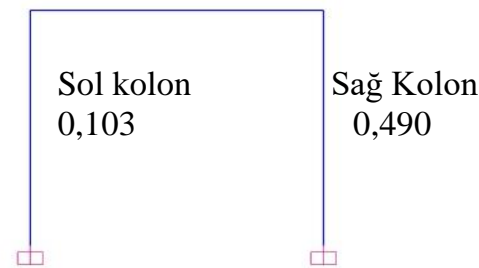

b.

Şekil 5.a. Çerçeve yükleri b. P/PcL oranı

Çerçevedeki maksimum moment noktalarında plastik mafsal oluşacağından kolon, kiriş uç noktalarına ve kiriş açıklığının orta noktasına plastik mafsal tanımlaması yapılmışıtır.

Tablo 3. Standartlara göre hesaplanan modelleme parametreleri ve kabul kriterleri

\begin{tabular}{|c|c|c|c|c|c|c|}
\hline \multirow{2}{*}{$\begin{array}{l}\text { Standart } \\
\text { Kiriş }\end{array}$} & \multicolumn{2}{|c|}{$\begin{array}{l}\text { Modelleme Parametreleri } \\
\text { Plastik dönme açısı } \\
\text { (radyan) }\end{array}$} & \multirow{2}{*}{$\begin{array}{l}\text { Artık dayanım } \\
\text { oranı } \\
\text { c }\end{array}$} & \multicolumn{3}{|c|}{$\begin{array}{l}\text { Kabul Kriterleri } \\
\text { Plastik dönme açısı (radyan) }\end{array}$} \\
\hline & $\mathbf{a}$ & b & & IO (SH) & LS (KH) & CP (GÖ) \\
\hline FEMA 356 & $4 \theta y$ & $6 \theta y$ & 0,2 & $0,25 \theta y$ & $2 \theta y$ & $3 \theta y$ \\
\hline ASCE 41-06 & $4 \theta y$ & $6 \theta y$ & 0,2 & $0,25 \theta y$ & $2 \theta y$ & $3 \theta y$ \\
\hline ASCE $41-13$ & $4 \theta y$ & $6 \theta y$ & 0,2 & $0,25 \theta y$ & $3 \theta y$ & $4 \theta y$ \\
\hline TBDY-2018 & --- & --- & --- & $0,25 \theta y$ & $3 \theta y$ & $4 \theta y$ \\
\hline Sol Kolon & $\mathbf{a}$ & b & c & IO (SH) & $\mathbf{L S}(\mathbf{K H})$ & CP (GÖ) \\
\hline FEMA 356 & $4 \theta y$ & $6 \theta y$ & 0,2 & $0,25 \theta y$ & $2 \theta y$ & $3 \theta y$ \\
\hline ASCE 41-06 & $4 \theta y$ & $6 \theta y$ & 0,2 & $0,25 \theta y$ & $2 \theta y$ & $3 \theta y$ \\
\hline ASCE $41-13$ & $4 \theta y$ & $6 \theta y$ & 0,2 & $0,25 \theta y$ & $3 \theta y$ & $4 \theta y$ \\
\hline TBDY-2018 & --- & --- & --- & $0,25 \theta y$ & $3 \theta y$ & $4 \theta y$ \\
\hline Sağ Kolon & $\mathbf{a}$ & b & c & IO (SH) & $\mathbf{L S}(\mathbf{K H})$ & CP (GÖ) \\
\hline FEMA 356 & $1 \theta y$ & $1,5 \theta y$ & 0,2 & $0,25 \theta y$ & $0,5 \theta y$ & $0,8 \theta y$ \\
\hline ASCE 41-06 & $1 \theta y$ & $1,5 \theta y$ & 0,2 & $0,25 \theta y$ & $0,5 \theta y$ & $0,8 \theta y$ \\
\hline ASCE $41-13$ & $1 \theta y$ & $1,5 \theta y$ & 0,2 & $0,25 \theta y$ & $1,2 \theta y$ & $1,2 \theta y$ \\
\hline TBDY-2018 & --- & --- & --- & $0,25 \theta y$ & $0,7 \theta y$ & $1 \theta y$ \\
\hline
\end{tabular}

Plastik mafsal tanımlamalarında kullanılan modelleme parametreleri ve şekil değiştirme sınır durumlarını belirleyen kabul kriterleri için hesaplanan değerler, Tablo 3 ile gösterilmiştir. Tablo 3' deki modelleme parametreleri ve kabul kriterleri, Tablo 1 ve Tablo 2' deki veriler kullanılarak hesaplanmıştır. TBDY- 
2018' e ait verilerin hesaplanmasında TBDY-2018' de yer alan Tablo 9-3'den yararlanılmıştır. Şekil 6 ile plastik mafsal modelleri üzerinde ilgili standartlara ait şekil değiştirme sınırları gösterilmiştir. Şekil 6.' daki $M$, momenti ve $Q$, dönme değerini simgelemekte olup Şekil 6.a' daki $M / M y=1,12$ üst değeri ile Şekil 6.b' deki $M / M y=1,03$ üst değeri, FEMA ve ASCE standartlarının önerdiği \%3 eğim kabulüne göre hesaplanmıştır. Akma dönmesi hesabında (1), (2), (3), (4) ve (5) denklemleri kullanılmıştır. Beklenen eğilme dayanımının hesabında (6) ve (7) denklemleri kullanılmıştır. Çerçeveye plastik mafsal tanımlaması ve yükleme durumları tanımlandıktan sonra sabit tek modlu itme analizi yapılmıştır. Geometri değişimlerinde ikinci mertebe etkileri dikkate alınmıştır. Yanal yük miktarı arttırılmıs olup, her bir yanal yük miktarı için çerçevedeki şekil değiştirme durumları ele alınan standartlar kapsamında gözlemlenmiştir.

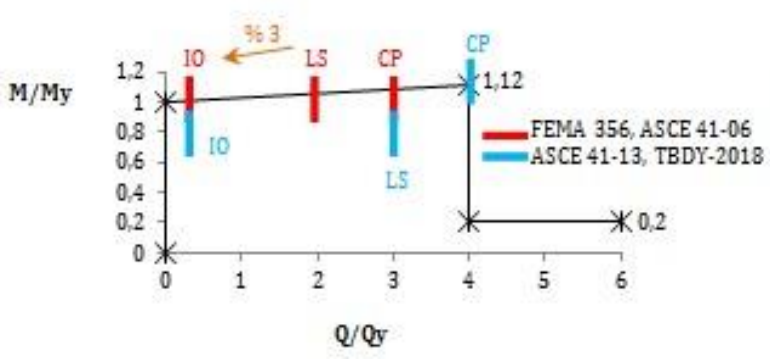

a.

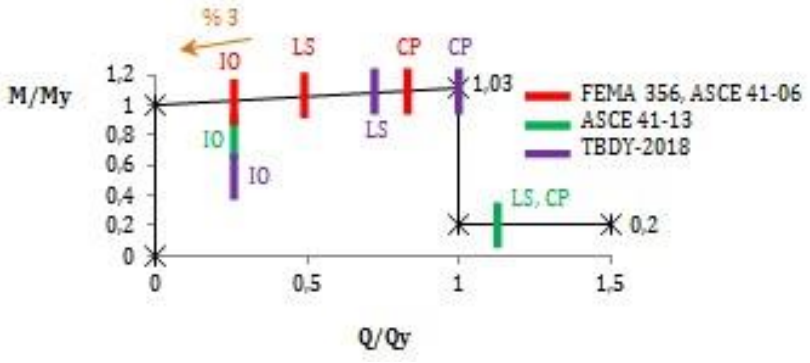

b.

Şekil 6.a. Kiriş ve sol kolon mafsal tanımı b. Sağ kolon mafsal tanımı

Çerçevenin taban kesme kuvveti - tepe deplasman değer çiftleriyle performans eğrisi oluşturulmuştur. Çerçeve, mekanizma durumuna geçinceye kadar itilmiştir. Şekil 7 ile performans eğrisinin gösterimi yapılmıştır. Düşey yüklerin dağılımına ve büyüklüğüne bağlı olarak çerçevede sadece sağ kolon alt ucunda plastik mafsal oluşumu incelenmiştir. Yükleme ile kolonlarda, $0,20 \leq P / P_{C L} \leq 0,50$ ve $0,20 \leq$ $P / P_{C}<0,50$ koşullarının sağlanabilmesi hedeflendiğinden çerçeve sünek davranış sergilememiştir.

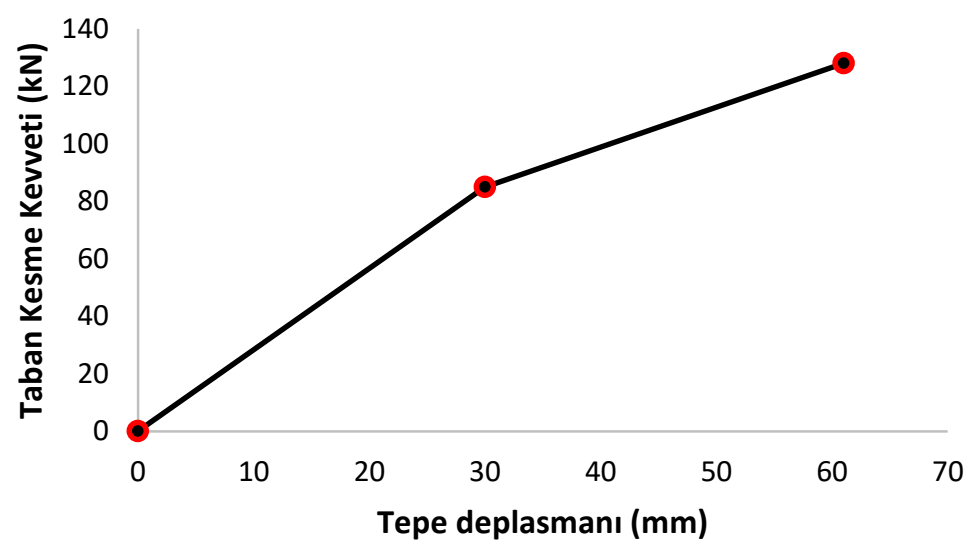

Şekil 7. Çerçeve performans eğrisi

$105 \mathrm{kN}$ ve $110 \mathrm{kN}$ yanal yük etkisindeki çerçevede oluşan şekil değiştirme dereceleri incelenmiştir. Tablo 4 ile $105 \mathrm{kN}$ ve $110 \mathrm{kN}$ yanal yük etkilerindeki kesitlerde oluşan hasar düzeyleri gösterilmiştir. Her iki yük durumu için FEMA-356 ve ASCE 41-06 standartlarında sonuçlar aynıdır. 105 kN yanal yük etkisinde ASCE 41-13 ve TBDY-2018 hasar düzeyleri aynı iken $110 \mathrm{kN}$ yanal yük etkisinde ise farklıdır. $105 \mathrm{kN}$ yük etkisi altında FEMA-356 ve ASCE 41-06 standartlarında hasar düzeyi Life Safety (LS) - Collapse Prevention (CP) arasındadır. ASCE41-13 standardında ve TBDY-2018' de hasar düzeyi Immediate Ocupancy (IO) - Life Safety (LS) arasındadır. $110 \mathrm{kN}$ yük etkisi altında FEMA-356 ve ASCE 41-06 
standartlarında hasar düzeyi Collapse Prevention (CP) düzeyinden ileridir. ASCE41-13 standardında hasar düzeyi Immediate Ocupancy (IO) - Life Safety (LS) arasındadır. TBDY-2018' de hasar düzeyi Life Safety (LS) - Collapse Prevention (CP) arasındadır.

Tablo 4. Hasar düzeylerinin karşılaştırılması

\begin{tabular}{|c|c|c|c|}
\hline \multirow[b]{2}{*}{ Standart } & \multicolumn{3}{|c|}{ Mafsallaşma (105 kN yanal yük etkisinde) } \\
\hline & Sol kolon & Kiriş & Sağ kolon alt ucu \\
\hline FEMA 356 & --- & --- & LS-CP \\
\hline ASCE 41-06 & --- & --- & LS-CP \\
\hline ASCE 41-13 & --- & --- & IO-LS \\
\hline \multirow{2}{*}{ TBDY-2018 } & --- & --- & IO-LS \\
\hline & \multicolumn{3}{|c|}{ Mafsallaşma (110 kN yanal yük etkisinde) } \\
\hline Standart & Sol kolon & Kiriş & Sağ kolon alt ucu \\
\hline FEMA 356 & --- & --- & $>\mathrm{CP}$ \\
\hline ASCE 41-06 & --- & --- & $>\mathrm{CP}$ \\
\hline ASCE 41-13 & --- & --- & IO-LS \\
\hline TBDY-2018 & --- & --- & LS-CP \\
\hline
\end{tabular}

\section{2 Íki katlı Çelik Yapı}

Yapı, iki katlı her iki yönde (X ve Y) tek açıklıklı çelik bir yapı ele alınmıştır. (X) ve (Y) yönlerindeki açıklık 5 metredir. Kat yüksekliği 3 metredir. Yapı zemine ankastre bağlanmıştır. Kirişler üzerinde (-Z) yönlü $20 \mathrm{kN}$ noktasal yük bulunmaktadır. Yükleme noktaları, Şekil 8.a ile gösterilmiştir. Yapı, zati ağırlık ve $20 \mathrm{kN}$ yüklemeden oluşan tek bir kombinasyon altında ÇYTHYDE-2018'e göre boyutlandırılmıştır. Boyutlandırmada Yük ve Dayanım Katsayıları ile Tasarım (YDKT) yaklaşımı kullanılmış olup, kolonlar için Bölüm 11' deki, kirişler için Bölüm 9' daki esaslar dikkate alınmıştır. Kolonlar HE240A ve kirişler HE200A olarak tasarlanmıştır. Zemin kat kolonları için P/PCL oranı 0,143 olarak hesaplanmış olup, Şekil 8.b ile kolonlardaki P/PCL oranları gösterilmiştir.

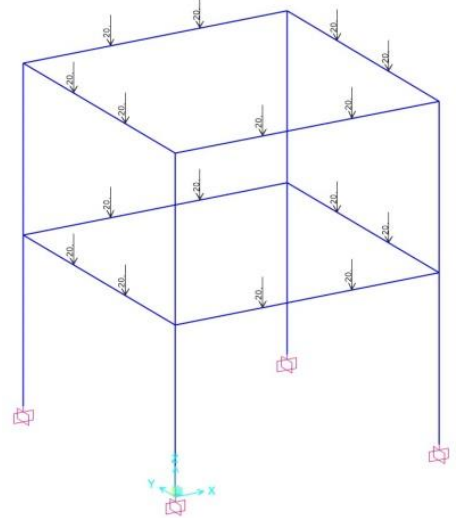

a.

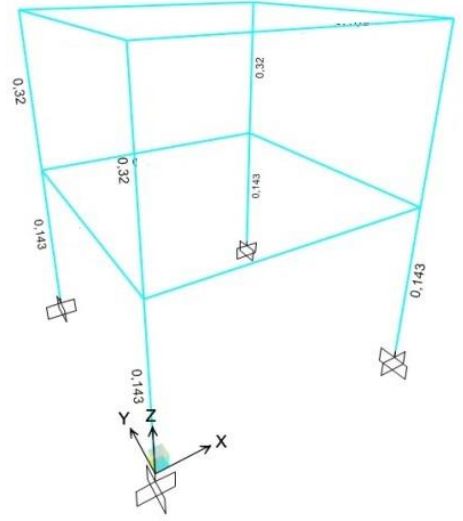

b.

Şekil 8. a. Üç boyutlu çelik yapı, b. P/PcL oranı

Plastik mafsal tanımlamalarında kullanılan modelleme parametreleri ve şekil değiştirme sınır durumlarını belirleyen kabul kriterleri için hesaplanan değerler, Tablo 5 ile gösterilmiştir. Tablo 5' deki modelleme parametreleri ve kabul kriterleri, Tablo 1 ve Tablo 2' deki veriler kullanılarak hesaplanmıştır. TBDY2018' e ait verilerin hesaplanmasında TBDY-2018' de yer alan Tablo 9-3'den yararlanılmıştır. Şekil 9 ile plastik mafsal modelleri üzerinde ilgili standartlara ait şekil değiştirme sınırları gösterilmiştir. Şekil 9' daki $M$, momenti ve $Q$, dönme değerini simgelemekte olup $M / M y=1,12$ üst değeri, FEMA ve ASCE standartlarının önerdiği \%3 eğim kabulüne göre hesaplanmıştır. Akma dönmesi hesabında (1), (2), (3), (4) ve (5) denklemleri kullanılmıştır. Beklenen eğilme dayanımının hesabında (6) ve (7) denklemleri 
kullanılmıştır. Tablo 5 ile gösterimi yapılan kabul kriterleri, kolon ve kiriş elemanlarındaki hasar düzeylerini işaret etmektedir. Plastik dönme açısı arttıkça elemandaki hasar artmaktadır.

Tablo 5. Standartlara göre hesaplanan modelleme parametreleri ve kabul kriterleri

\begin{tabular}{|c|c|c|c|c|c|c|}
\hline \multirow{2}{*}{$\begin{array}{l}\text { Standart } \\
\text { Kiriş }\end{array}$} & \multicolumn{2}{|c|}{$\begin{array}{l}\text { Modelleme Parametreleri } \\
\text { Plastik dönme açısı } \\
\text { (radyan) }\end{array}$} & \multirow{2}{*}{$\begin{array}{l}\text { Artık dayanım } \\
\text { oranı } \\
\text { c }\end{array}$} & \multicolumn{2}{|c|}{$\begin{array}{l}\text { Kabul Kriterleri } \\
\text { Plastik dönme açısı (radyan) }\end{array}$} & \multirow[b]{2}{*}{ CP (GÖ) } \\
\hline & $\overline{\mathbf{a}}$ & $\bar{b}$ & & IO (SH) & LS (KH) & \\
\hline FEMA 356 & $4 \theta y$ & $6 \theta y$ & 0,2 & $0,25 \theta y$ & $2 \theta y$ & $3 \theta y$ \\
\hline ASCE 41-06 & $4 \theta y$ & $6 \theta y$ & 0,2 & $0,25 \theta y$ & $2 \theta y$ & $3 \theta y$ \\
\hline ASCE 41-13 & $4 \theta y$ & $6 \theta y$ & 0,2 & $0,25 \theta y$ & $3 \theta y$ & $4 \theta y$ \\
\hline TBDY-2018 & --- & --- & --- & $0,25 \theta y$ & $3 \theta y$ & $4 \theta y$ \\
\hline Kolon & $\mathbf{a}$ & b & c & IO (SH) & LS (KH) & CP (GÖ) \\
\hline FEMA 356 & $4 \theta y$ & $6 \theta y$ & 0,2 & $0,25 \theta y$ & $2 \theta y$ & $3 \theta y$ \\
\hline ASCE 41-06 & $4 \theta y$ & $6 \theta y$ & 0,2 & $0,25 \theta y$ & $2 \theta y$ & $3 \theta y$ \\
\hline ASCE 41-13 & $4 \theta y$ & $6 \theta y$ & 0,2 & $0,25 \theta y$ & $3 \theta y$ & $4 \theta y$ \\
\hline TBDY-2018 & --- & -- & --- & $0,25 \theta y$ & $3 \theta y$ & $4 \theta y$ \\
\hline
\end{tabular}

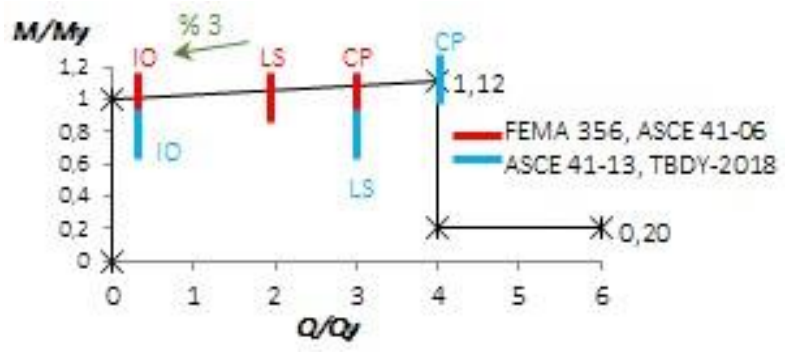

Şekil 9. Kolon-kiriş plastik mafsal tanımı

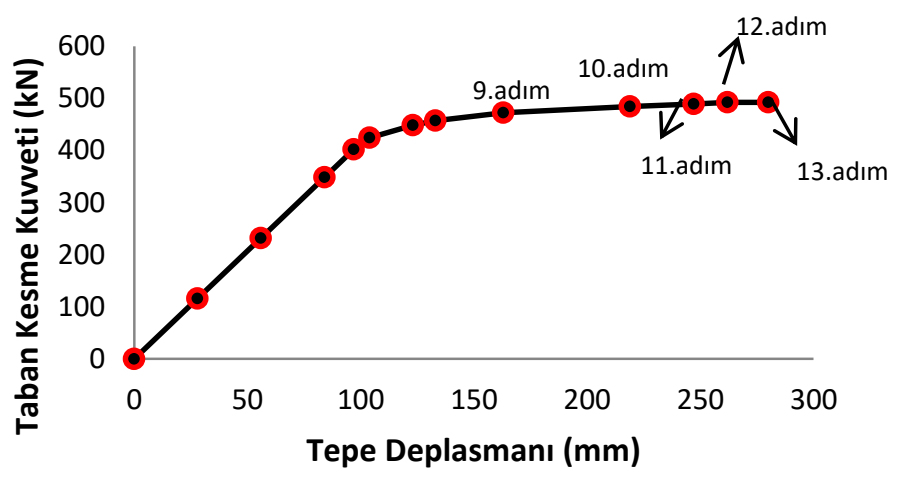

Şekil 10. Performans eğrisi

Yapı, sadece X yönü için sabit tek modlu statik itme analizi ile incelenmiştir. Yanal yük şablonu olarak üçgen dağılım benimsenmiştir. Zemin kat seviyesindeki dügüm noktalarında $X$ yönündeki yanal yük bir birim iken birinci kat düğüm noktalarında iki birimdir. Geometri değişimlerinde ikinci mertebe etkileri dikkate alınmıştır. Kolon-kiriş birleşimlerinin moment aktardığı ve birleşimlerde plastik mafsal oluşmadığ 1 kabul edilmiştir. Kolon ve kiriş kesitleri, kuvvetli yönleri doğrultusunda analiz edilmiştir. Yanal yük etkisi altında kolon alt ve üst uç noktaları ile kiriş başlangıç ve bitiş noktalarında plastik mafsal oluşacağı ön görülmüştür. Her adımda yanal yük miktarı arttırılarak yapıdaki plastik mafsal oluşumunun 
artması sağlanmıştır. Her bir yanal yük miktarı için yapıdaki şekil değiştirme durumları ele alınan standartlar kapsamında incelenmiştir. Yapının taban kesme kuvveti - tepe deplasman değer çiftleriyle performans eğrisi oluşturulmuştur. Yap1, mekanizma durumuna geçinceye kadar itilmiştir. Şekil 10 ile performans eğrisinin gösterimi yapılmıştır. Şekil 10' dan de anlaşılacağı üzere statik itme analizi, 13 adımda gerçekleştirilmiştir.

Şekil 11, 13, 14 ve 15 ile yapıdaki hasar düzeylerinin gösterimi yapılmıştır. Birinci adımdan dokuzuncu adıma kadar dokuzuncu adımda dahil olmak üzere tüm standartlardaki hasar düzeyleri aynıdır. Onuncu adımda hasar düzeyleri farklılık göstermiştir. Tablo 5 incelendiğinde FEMA 356 ve ASCE 41-06' deki kabul kriterleri ile ASCE 41-13 ve TBDY-2018' deki kabul kriterletinin aynı olduğu görülmektedir. Şekil 11.a., 13.a., 14.a. ve 15.a. ile gösterimi yapılan hasar düzeyleri FEMA 356 ve ASCE 41-06 için verilmişken Şekil 11.b., 13.b., 14.b. ve 15.b. ile gösterimi yapılan hasar düzeyleri ASCE 41-13 ve TBDY2018 için verilmiştir.

Zemin kat kolonlarının alt uçlarında, $\mathrm{X}$ yönündeki zemin kat ve birinci kat kirişlerinin başlangıç (sol uç) ve bitiş (sağ uç) noktalarında plastik mafsal oluşumu gözlemlenmiştir. Göçme mekanizması, zemin kat kolon alt uçlarındaki plastik mafsal oluşumuyla meydana gelmiştir. Hasar düzeylerinin karşılaştırması, Tablo 6 ile gösterilmiştir.

Tablo 6. Hasar düzeylerinin karşılaștırılması

\begin{tabular}{|c|c|c|c|c|c|c|c|c|c|c|}
\hline Standart & $\begin{array}{l}\text { Kolon } \\
\text { hd }\end{array}$ & $\begin{array}{l}\text { ki plasti } \\
\text { Kolon } \\
\text { pdd } \\
(\mathrm{rad})\end{array}$ & $\begin{array}{l}\text { mafsal olu } \\
\text { ZK } \\
\text { kiriş } \\
\text { sol ucu } \\
\text { hd }\end{array}$ & $\begin{array}{l}\text { umu } \\
\text { ZK kiriş } \\
\text { sol ucu } \\
\text { pdd (rad) }\end{array}$ & $\begin{array}{lr}\text { ZK } & \text { kiriş } \\
\text { sağ } & \text { ucu } \\
\text { hd } & \end{array}$ & $\begin{array}{l}\text { ZK } \quad \text { kiriş } \\
\text { sağ } \quad \text { ucu } \\
\text { pdd (rad) }\end{array}$ & $\begin{array}{l}\text { BK } \\
\text { kiriş } \\
\text { sol ucu } \\
\text { hd }\end{array}$ & $\begin{array}{l}\text { BK kiriş } \\
\text { sol ucu } \\
\text { pdd (rad) }\end{array}$ & $\begin{array}{lr}\text { BK } & \text { kiriş } \\
\text { sağ } & \text { ucu } \\
\text { hd } & \end{array}$ & $\begin{array}{lr}\text { BK } & \text { kiriş } \\
\text { sağ } & \text { ucu } \\
\text { pdd (rad) }\end{array}$ \\
\hline FEMA 356 & IO - LS & \multirow{4}{*}{0,0236} & IO - LS & \multirow{4}{*}{0,0289} & IO - LS & \multirow{4}{*}{0,0286} & --- & \multirow{4}{*}{0,0215} & IO - LS & \multirow{4}{*}{0,0204} \\
\hline ASCE 41-06 & IO - LS & & IO - LS & & IO - LS & & --- & & IO - LS & \\
\hline ASCE $41-13$ & IO - LS & & IO - LS & & IO - LS & & --- & & IO - LS & \\
\hline TBDY-2018 & IO - LS & & IO - LS & & IO - LS & & --- & & IO - LS & \\
\hline & \multicolumn{6}{|c|}{ 10. adımdaki plastik mafsal oluşumu } & & & & \\
\hline Standart & $\begin{array}{l}\text { Kolon } \\
\text { hd }\end{array}$ & $\begin{array}{l}\text { Kolon } \\
\text { pdd } \\
\text { (rad) }\end{array}$ & $\begin{array}{l}\text { ZK } \\
\text { kiriş } \\
\text { sol ucu } \\
\text { hd }\end{array}$ & $\begin{array}{l}\text { ZK kiriş } \\
\text { sol ucu } \\
\text { pdd (rad) }\end{array}$ & $\begin{array}{lr}\text { ZK } & \text { kiriş } \\
\text { sağ } & \text { ucu } \\
\text { hd } & \end{array}$ & $\begin{array}{l}\text { ZK } \quad \text { kiriş } \\
\text { sağ } \quad \text { ucu } \\
\text { pdd (rad) }\end{array}$ & $\begin{array}{l}\text { BK } \\
\text { kiriş } \\
\text { sol ucu } \\
\text { hd }\end{array}$ & $\begin{array}{l}\text { BK kiriş } \\
\text { sol ucu } \\
\text { pdd (rad) }\end{array}$ & $\begin{array}{lr}\text { BK } & \text { kiriş } \\
\text { sağ } & \text { ucu } \\
\text { hd } & \end{array}$ & $\begin{array}{lr}\text { BK } & \text { kiriş } \\
\text { sağ } & \text { ucu } \\
\text { pdd (rad) }\end{array}$ \\
\hline FEMA 356 & $>\mathrm{CP}$ & \multirow{4}{*}{0,0317} & IO - LS & \multirow{4}{*}{0,0388} & LS -CP & \multirow{4}{*}{0,0384} & IO - LS & \multirow{4}{*}{0,0313} & IO - LS & \multirow{4}{*}{0,0302} \\
\hline ASCE 41-06 & $>\mathrm{CP}$ & & IO - LS & & LS -CP & & IO - LS & & IO - LS & \\
\hline ASCE 41-13 & LS -CP & & IO - LS & & IO - LS & & IO - LS & & IO - LS & \\
\hline TBDY-2018 & LS -CP & & IO - LS & & IO - LS & & IO - LS & & IO - LS & \\
\hline & \multicolumn{6}{|c|}{$\begin{array}{l}\text { 12. adımdaki plastik mafsal oluşumu } \\
Z \mathrm{~K}\end{array}$} & & & & \\
\hline Standart & $\begin{array}{l}\text { Kolon } \\
\text { hd }\end{array}$ & $\begin{array}{l}\text { Kolon } \\
\text { pdd } \\
(\mathrm{rad})\end{array}$ & $\begin{array}{l}\text { ZK } \\
\text { kiriş } \\
\text { sol ucu } \\
\text { hd }\end{array}$ & $\begin{array}{l}\text { ZK kiriş } \\
\text { sol ucu } \\
\text { pdd (rad) }\end{array}$ & $\begin{array}{lr}\text { ZK } & \text { kiriş } \\
\text { sağ } & \text { ucu } \\
\text { hd } & \end{array}$ & $\begin{array}{lr}\text { ZK } & \text { kiriş } \\
\text { sağ } & \text { ucu } \\
\text { pdd (rad) }\end{array}$ & $\begin{array}{l}\text { BK } \\
\text { kiriş } \\
\text { sol ucu } \\
\text { hd }\end{array}$ & $\begin{array}{l}\text { BK kiriş } \\
\text { sol ucu } \\
\text { pdd (rad) }\end{array}$ & $\begin{array}{lr}\text { BK } & \text { kiriş } \\
\text { sağ } & \text { ucu } \\
\text { hd } & \end{array}$ & $\begin{array}{lr}\text { BK } & \text { kiriş } \\
\text { sağ } & \text { ucu } \\
\text { pdd }(\mathrm{rad})\end{array}$ \\
\hline FEMA 356 & $>\mathrm{CP}$ & \multirow{4}{*}{0,0378} & LS -CP & \multirow{4}{*}{0,0463} & LS -CP & \multirow{4}{*}{0,0459} & IO - LS & \multirow{4}{*}{0,0387} & IO - LS & \multirow{4}{*}{0,0376} \\
\hline ASCE 41-06 & $>\mathrm{CP}$ & & LS -CP & & LS -CP & & IO - LS & & IO - LS & \\
\hline ASCE 41-13 & LS -CP & & IO - LS & & IO - LS & & IO - LS & & IO - LS & \\
\hline TBDY-2018 & LS -CP & & IO - LS & & IO - LS & & IO - LS & & IO - LS & \\
\hline & \multicolumn{6}{|c|}{$\begin{array}{l}\text { 13. adımdaki plastik mafsal oluşumu } \\
\mathrm{ZK}\end{array}$} & & & & \\
\hline Standart & $\begin{array}{l}\text { Kolon } \\
\text { hd }\end{array}$ & $\begin{array}{l}\text { Kolon } \\
\text { pdd } \\
\text { (rad) }\end{array}$ & $\begin{array}{l}\text { ZK } \\
\text { kiriş } \\
\text { sol ucu } \\
\text { hd }\end{array}$ & $\begin{array}{l}\text { ZK kiriş } \\
\text { sol ucu } \\
\text { pdd (rad) }\end{array}$ & $\begin{array}{lr}\text { ZK } & \text { kiriş } \\
\text { sağ } & \text { ucu } \\
\text { hd } & \end{array}$ & $\begin{array}{l}\text { ZK } \quad \text { kiriş } \\
\text { sağ } \quad \text { ucu } \\
\text { pdd (rad) }\end{array}$ & $\begin{array}{l}\text { BK } \\
\text { kiriş } \\
\text { sol ucu } \\
\text { hd }\end{array}$ & $\begin{array}{l}\text { BK kiriş } \\
\text { sol ucu } \\
\text { pdd (rad) }\end{array}$ & $\begin{array}{lr}\text { BK } & \text { kiriş } \\
\text { sağ } & \text { ucu } \\
\text { hd } & \end{array}$ & $\begin{array}{lr}\text { BK } & \text { kiriş } \\
\text { sağ } & \text { ucu } \\
\text { pdd (rad) }\end{array}$ \\
\hline FEMA 356 & $>\mathrm{CP}$ & \multirow{4}{*}{0,0403} & LS -CP & \multirow{4}{*}{0,0494} & LS -CP & \multirow{4}{*}{0,0489} & IO - LS & \multirow{4}{*}{0,0416} & LS -CP & \multirow{4}{*}{0,0405} \\
\hline ASCE 41-06 & $>\mathrm{CP}$ & & LS -CP & & LS -CP & & IO - LS & & LS -CP & \\
\hline ASCE 41-13 & $>\mathrm{CP}$ & & IO - LS & & IO - LS & & IO - LS & & IO - LS & \\
\hline TBDY-2018 & $>\mathrm{CP}$ & & IO - LS & & IO - LS & & IO - LS & & IO - LS & \\
\hline
\end{tabular}

Tablo 6'daki hd, hasar düzeyini; pdd, plastik dönme değerini; ZK, zemin kat1; BK, birinci katı simgelemektedir. Yap1 simetrik olduğundan zemin kat kolonlarındaki, zemin kat ve birinci kat kirişlerindeki hasar düzeyleri ve plastik dönme değerleri birbirleri içerisinde aynıdır. Bu nedenle, Tablo 6'da tek bir kolon ve hem zemin hem de birinci kattaki tek bir kiriş için gösterim yapılmıştır. 


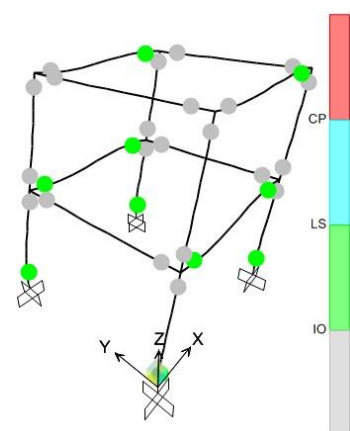

a.

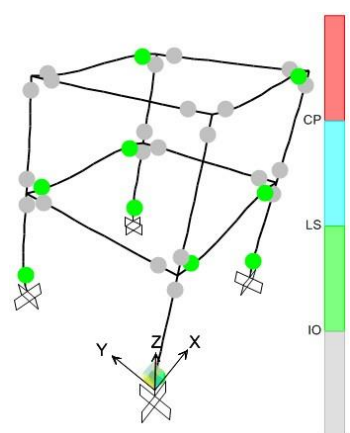

b.

Şekil 11. Dokuzuncu adımdaki plastik mafsal oluşumu

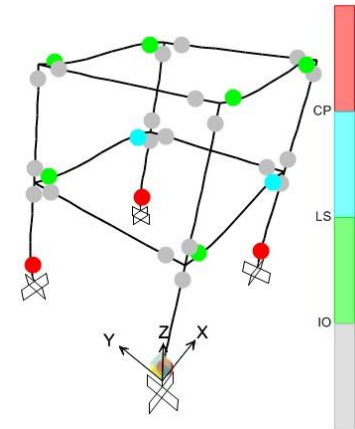

a.

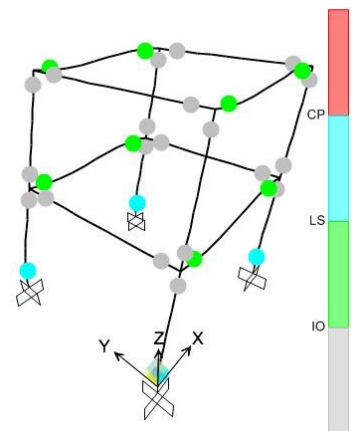

b.

Şekil 12. Onuncu adımdaki plastik mafsal oluşumu

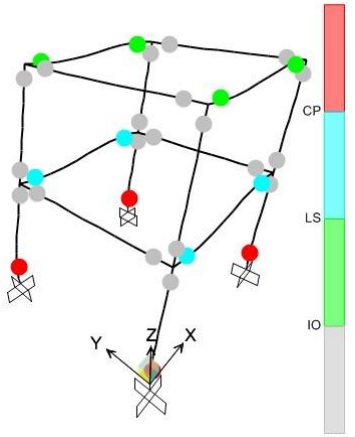

a.

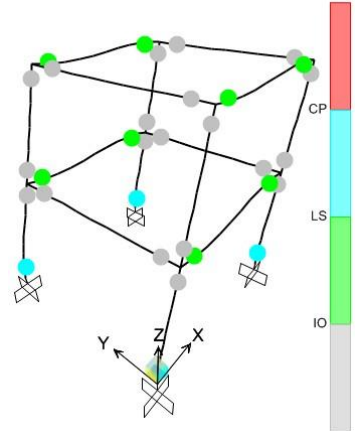

b.

Şekil 13. On ikinci adımdaki plastik mafsal oluşumu

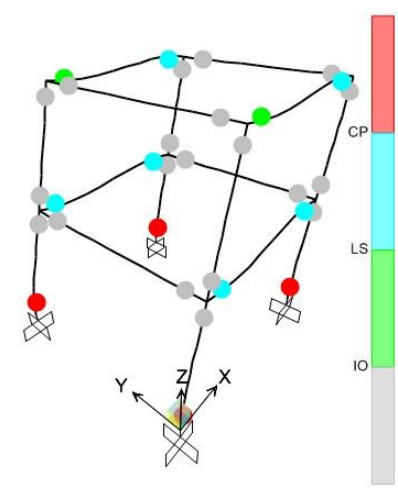

a.

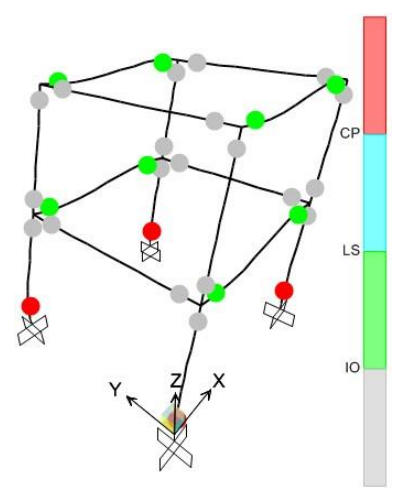

b.

Şekil 14. On üçüncü adımdaki plastik mafsal oluşumu 


\section{TARTIŞMA}

TBDY-2018, betonarme ve çelik yapıların deprem performans kriterlerini içermektedir. Yapılan kapsamlı liteartür araştırmasıyla TBDY-2018' de yer alan çelik kiriş ve kolon elemanlarının şekil değiştirme sınır değerlerine dair bir çalışma olmadığı görülmüştür. Ancak [17] ile betonarme elemanlar için Deprem Bölgelerinde Yapılacak Binalar Hakkında Yönetmelik (DBYBHY-2007) ile TBDY2018'deki şekil değiştirme sınır durumlarının karşılaştırması yapılmıştır. [17] ile yapılan çalışma hem betonarme yapı elemanlarını içermesi hem de ulusal yönetmelik dışına çıkmaması açısından bu çalışmadan ayrılmaktadır.

Çalışma ile çelik kolon ve kiriş plastik mafsal parametrelerinin ve şekil değiştirme sınır değerlerinin farklı standartlar kullanılarak karşılaştırması yapılmıştır. FEMA 356, ASCE 41-06, ASCE 41-13 standartları ve TBDY-2018 incelenmiştir. Çalışma kapsamında tek katlı düzlem çelik bir çerçeve ve iki katlı her iki yönde (X ve Y) tek açıklıklı çelik bir yapı ele alınmıştır. FEMA 356, ASCE 41-06 ve ASCE 41-13 standartlarında plastik mafsal modellemelerine, şekil değiştirme sınır değerlerine, akma dönmesi hesabına ve beklenen eğilme dayanımı hesabına yer verilmiştir. Buna karşın TBDY-2018' de plastik mafsal model parametrelerinin bulunmadığı ve TBDY-2018'in plastik mafsal tanımına yönelik beklenen eğilme dayanımında ilişkin bir denklem önermediği belirlenmiştir. TBDY-2018, çelik yapıların deprem performansının doğrusal olmayan prosedüre göre belirlenmesinde eksik kalmaktadır.

Ülkemizdeki yapı stoğunun, önemli bir bölümünü betonarme binaların oluşturduğu düşünülürse, betonarme binalar için farklı standarlardaki mevcut bina değerlendirme prosedürlerinin TBDY-2018' deki prosedürler ile karşılaştırılması önerilmektedir.

\section{SONUÇ}

Deprem etkisindeki yeni yapılacak çelik yapıların tasarımında ya da mevcut çelik yapıların performans değerlendirmesinde artan yanal yükler altında kolon ve kiriş elemanlarında oluşması muhtemel hasarın tahmini, yapının stabilitesini koruma ve göçmesini engelleme noktasında büyük önem taşımaktadır. Hasar tahmininde plastik mafsal tanımı ve şekil değiştirme sınır değerleri (kabul kriterleri) kullanılmaktadır. Plastik mafsal tanımıyla taşıyıcı elemanın doğrusal olmayan davranışı modellenirken şekil değiştirme sınırlarıyla da hasarın ne ölçüde olacağı tahmin edilmeye çalışılmaktadır.

Tablo 1 incelendiğinde FEMA 356, ASCE 41-06 ve ASCE 41-13 standartlarındaki modelleme parametrelerinin ve IO kabul kriterinin aynı olduğu buna karşın LS ve CP kriterlerinin farklı olduğu, Tablo 1 ve 2 incelendiğinde TBDY-2018' deki kabul kriterlerinin diğer üç standarttan farklı olduğu görülmüştür. Kabul kriterleri kapsamında tüm standartların kiriş elemanı için kesit narinliğini, kolon elemanı için hem kesit narinliğini hem de eksenel yük düzeyini dikkate aldığı belirlenmiştir. Tablo 1 ve 2' deki kabul kriterleri karşılaştırıldığında TBDY-2018 değerlerinin diğer standartlardan farklı olduğu görülmüştür. Şekil 1.' deki zaman akış şeması dikkate alındığında önce FEMA 356 sonra ASCE 41-06 sonra da ASCE 41-13 standartları oluşturulmuştur. Bu nedenle en doğru veri olarak ASCE 41-13 sınır değerleri kabul edilmiştir. TBDY-2018' deki kolon-eğilme $\left[\left(0,20 \leq \mathrm{P} / \mathrm{P}_{\mathrm{C}}<0,50\right)\right.$ i. süneklik düzeyi yüksek] koşulundaki SH kriteri ASCE 41-13' den farklı olup diğer beş koşul için aynıdır. TBDY-2018' deki kolon-eğilme $\left[\left(\mathrm{P} / \mathrm{P}_{\mathrm{C}}<0,20\right)\right.$ ii. süneklik düzeyi sınırl1] ve kiriş-eğilme [ii. süneklik düzeyi sınırl1] koşullarındaki KH ve GÖ kriteri ASCE 41-13 ile aynı olup diğer koşullar için farklıdır.

Bölüm 3.1' deki Düzlem Çelik Çerçeve, farklı eksenel yük düzeyindeki iki kolondan ve bir kirişten oluşmaktadır. Şekil 7.a incelendiğinde TBDY-2018 ile ASCE 41-13 standartlarının kabul kriterlerinin aynı olduğu ancak Şekil 7.b' de ise farklı oldukları tespit edilmiştir. Şekil 8 ile sabit tek modlu itme analizi sonucunda çerçeve performans eğrisi çizilmiştir. Çerçeve mekanizması oluşmaktadır. Analiz ile sağ kolon alt ucunda plastik mafsal oluşumu gözlenmiştir. Tablo 4 ile farklı standartlardaki hasar sınır durumlarına yer verilmiştir. $105 \mathrm{kN}$ yanal yük etkisindeki çerçeve sağ kolon alt ucundaki hasar, FEMA 356 ve ASCE 41-06 standartlarına göre LS - CP, ASCE 41-13 ve TBDY-2018 standartlarına göre IO - LS 
sınırları arasındadır. $110 \mathrm{kN}$ yanal yük etkisinde tüm standartlarda hasar artmıştır. FEMA 356 ve ASCE 41-06 standartlarına göre hasar > CP, ASCE 41-13 standardında IO - LS sınırları arasında ve TBDY-2018 yönetmeliğine göre LS - CP sinırları arasındadır.

Bölüm 3.2' deki İki Katlı Çelik Yapı kapsamında Tablo 5 incelendiğinde FEMA 356, ASCE 41-06 ve ASCE 41-13 standartlarındaki modelleme parametrelerinin aynı olduğu, TBDY-2018' de model parametrelerinin bulunmadığı görülmüştür. Öte yandan kabul kriterleri olarak plastik dönme açısı sınır değerleri, FEMA 356 ve ASCE 41-06 değerleri aynı iken ASCE 41-13 ve TBDY-2018 değerleri de aynıdır. Tablo 6 incelendiğinde tüm elemanlardaki hasar düzeyleri, FEMA 356 ve ASCE 41-06 için aynı iken ASCE 41-13 ve TBDY-2018 için de aynıdır. Tüm elemanlardaki plastik dönme değerleri arttıkça hasar düzeyinin arttığı belirlenmiştir. Onuncu, onikinci ve onüçüncü adımlardaki plastik mafsal oluşumlarında standartlar arasındaki hasar düzeylerinde farklılıklar olduğu görülmüştür. Süneklik düzeyi sınırlı kirişler ve eksenel yük düzeyi $\left(\mathrm{P} / \mathrm{P}_{\mathrm{C}}<0,20\right)$ koşulu altındaki süneklik düzeyi sınırlı kolonlar için TBDY-2018 ile ASCE 41-13' deki plastik dönme açısında bağlı olarak şekil değiştirme sınır durumlarının aynı olduğu, bir başka deyişle hasar tahminlerinin aynı olduğu tespit edilmiş̧ir.

TBDY-2018' deki Tablo 5C.1. ile 5C.2.' de yer alan plastik dönme sinır değerlerinin ASCE 41-13 standardında yer alan sınır değerleriyle birebir uyumlu olmadığı, TBDY-2018' de plastik mafsal parametrelerinin ve beklenen eğilme dayanımlarının hesabına ilişkin herhangi bir denklemin bulunmadığı görülmüş̧ür. FEMA 356 ve ASCE 41-06 standartları, ASCE 41-13 standardı ve TBDY-2018 dikkate alınarak yapılacak hasar tahminlerinde kolon ve kiriş elemanları için farklı hasar durumlarının tahmin edileceği tespit edilmiştir. Kiriş ve kolon elemanlarındaki hasar tahmini için TBDY-2018' e plastik mafsal parametrelerinin ve beklenen eğilme dayanımı hesabında kullanılacak denklemlerin eklenmesi gerekmektedir.

\section{REFERANSLAR}

[1] Šipoš, T.K., Hadzıma-Nyarko, M., 2018, "Seismic Risk of Croatian Cities Based on Building's vulnerability", Tehnički Vjesnik, Cilt 25, Sayı 4, ss. 1088-1094.

[2] Acevedo, A.B., Yepes-Estrada, C., González, D., Silva, V., Mora, M., Arcila, M., Posada, G., 2020, "Seismic risk assessment for the residential buildings of the major three cities in Colombia: Bogotá, Medellín, and Cali”, Earthquake Spectra, Cilt 36, Sayı: 1, ss. 298-320.

[3] Lignos, D.G., Krawinkler, H., Whittaker, A.S., 2010, 'Predictionand Validation of Sidesway Collapse of Two Scale Models of a 4 Story Steel Moment Frame", Earthquake Engineering and Structural Dynamics, Cilt 40, Say1 7, ss. 807-825.

[4] Gioncu, V., Mosoarca, M., Anastasiadis, A., 2012, 'Prediction of Available Rotation Capacity and Ductility of Wide-Flange Beams: Part 1:DUCTROT-M Computer Program', Journal of Constructional Steel Research, Cilt 69, ss. 8-19.

[5] Anastasiadis, A., Mosoarca, M., Gioncu, V., 2012, "Prediction of Available Rotation Capacity and Ductility of Wide-FlangeBeams: Part 2: Applications', Journal of Constructional Steel Research, Cilt 68, ss. $176-191$.

[6] Latour, M., Rizzano, G., 2013, 'A Theoretical Model for Predicting the Rotational Capacity of Steel Base Joints", Journal of Constructional Steel Research, Cilt 91, ss. 89-99.

[7] Stylianidis, P.M., Nethercot, D.A., 2015, ' Modelling of Connection Behaviour for Progressive Collapse Analysis", Journal of Constructional Steel Research, Cilt 113, ss. 169-184. 
[8] Falborski, T., Torres-Rodas, P., Zareian, F., Kanvinde, A., 2020, 'Effect of Base-Connection Strength and Ductility on the Seismic Performance of Steel Moment-Resisting Frames", Journal of Structural Engineering, Cilt 146, Say1 5, ss. 1-15.

[9] Torabian, S., Schafer, B.W., 2014, '’Role of Local Slenderness in the Rotation Capacity of Structural Steel Members", Journal of Constructional Steel Research, Cilt 95, ss. 32-43.

[10] Elkady, A., Lignos, D.G., 2015, '’Analytical Investigation of the Cyclic Behavior and Plastic Hinge Formation in Deep Wide-Flange Steel Beam-Columns", Bull Earthquake Engineering, Cilt 13, ss. 10971118.

[11] Araújo, M., Macedo, L., Castro, J.M., 2017, 'Evaluation of the Rotation Capacity Limits of Steel Members Defined in EC8-3", Journal of Constructional Steel Research, Cilt 135, ss. 11-29.

[12] EN 1993-8-3., 2005, Eurocode 8: Design of structures for earthquake resistance - Part 3: Assessment and retrofitting of buildings, European Committee for Standardization, Brussel.

[13] ASCE 41-06., 2007, Seismic Evaluation of Existing Buildings, American Society of Civil Engineers, Reston, Virginia, A.B.D.

[14] ASCE 41-13., 2014, Seismic Evaluation and Retrofit of Existing Building, American Society of Civil Engineers, Reston, Virginia, A.B.D.

[15] DBYBHY-2007., Deprem Bölgelerinde Yapılacak Binalar Hakkında Yönetmelik, Bayındırlık ve İskân Bakanlığı, Ankara.

[16] TBDY-2018., Türkiye Bina Deprem Yönetmeliği, İç İşleri Bakanlığı, Afet ve Acil Durum Yönetimi Başkanlığı, Ankara.

[17] Ulutaş, H., 2019, 'DBYBHY (2007) ve TBDY (2018) Deprem Yönetmeliklerinin Kesit Hasar Sınırları Açısından Kıyaslanması”, Avrupa Bilim ve Teknoloji Dergisi, Cilt 17, ss. 351-359.

[18] Gardner, L., Yun, X., Fieber, A., Macorini, L., 2019, 'Steel Design by Advanced Analysis: Material Modeling and Strain Limits", Engineering, Cilt 5, ss. 243-249.

[19] Wong M. Bill., 2009, Plastic Analysis and Design of Steel Structures, Butterworth-Heinemann, Burlington, A.B.D.

[20] Çakıroğlu, A, Özer, E., 1980, Malzeme ve Geometri Bakımından Lineer Olmayan Sistemler, Cilt 1, Matbaa Teknisyenleri Basım Evi, İstanbul.

[21] Chan, S.L., Chui, P.P.T., 2000, Non-Linear Static and Cyclic Analysis of Steel Frames With Semi-Rijid Connections, Elsevier Science.

[22] FEMA 178., 1994, NEHRP Handbook for the Seismic Evaluation of Existing Buildings, Federal Emergency Management Agency, Reston, Virginia, A.B.D.

[23] FEMA 273., 1997, NEHRP Guidelines for the Seismic Rehabilitation of Buildings, Federal Emergency Management Agency, Reston, Virginia, A.B.D.

[24] FEMA 310., 1998, Handbook for the Seismic Evaluation of Buildings, Federal Emergency Management Agency, Reston, Virginia, A.B.D. 
[25] FEMA 356., 2000, Prestandard and Commentary for the Seismic Rehabilitation of Buildings, Federal Emergency Management Agency, Reston, Virginia, A.B.D.

[26] ASCE 31-03., 2002, Seismic Evaluation of Existing Buildings, American Society of Civil Engineers, Reston, Virginia, A.B.D.

[27] ASCE 41-17., 2017, Seismic Evaluation and Retrofit of Existing Building, American Society of Civil Engineers, Reston, Virginia, A.B.D.

[28] ÇYTHYDE-2018., Çelik Yapıların Tasarım, Hesap ve Yapımına Dair Esaslar, Çevre ve Şehircilik Bakanlı̆̆ 1 , Ankara.

[29] EN 1993-1-1., 2014, Eurocode 3: Design of structures - Part 1-1: General rules and rules for building. European Committee for Standardization, Brussel.

[30] EN 10025-2., 2019, Hot rolled products of structural steels- Part 2: Technical delivery conditions for nonalloy structural steels. European Committee for Standardization, Brussel. 